Autobiography is a treacherous undertaking. The more you cover up, the more you are likely to reveal. Someone once wrote that he had never seen Francis Crick in a modest mood; it was a memorable phrase. Now, at long last, we are hearing from the man himself. Only in one respect do I think him misleading and immodest. He makes it all seem too easy. I have watched him at several Cold Spring Harbor symposia. He would sit in the front row, listen intently to every talk, interrogate, dominate, and end the week in a state of exhaustion. It seems for him there is nothing between rest and over- drive. This capacity for prolonged and intense concentration is one side to his character that does not appear in the book.

Many readers will be struck by the thought that Crick belongs to a bygone age, when biologists were given time to think. What granting agency today would give several years of support to a young scientist who just wanted to build models? What 30 year old would now dare to embark on such a perilous pursuit?

John Cairns is a Professor in the Department of Cancer Biology, Harvard School of Public Health, 665 Huntington Avenue, Boston, Massachusetts 02115, USA.

\section{"Amoebas at the start were not complex They tore themselves apart and started sex"}

\section{Mark Ridley}

The Evolution of Complexity By Means of Natural Selection. By John Tyler Bonner. Princeton University Press:1988. Pp.260. Hbk \$40; pbk\$13.95.

WE DO NOT really know how many species are alive today. Until recently, the estimate was 'a few' million, a rough extrapolation from the fact that taxonomists have described about a million modern species. The latest estimate is a factor of ten higher, at about 3-4 $310^{7}$, the increase having been inspired by detailed sampling of the beetles in tropical trees.

Therefore, between the origin of life and the modern variety of forms, there must have been more than 30 million different lineages. It is difficult to estimate how many more. George Gaylord Simpson once guessed that $4 \times 10^{9}$ species have lived throughout evolutionary history. His estimate should probably now be revised upwards; but many of those species would have shared the same lineages, so the actual number of lineages must be between the total number of species that have ever lived and the total number alive today. Maybe $10^{9}$ is a reasonable guess. Now, one but only one of those lineages runs through a long series of extinct forms from the origin of life to ourselves. A sure method of making many biologists hopping mad is to identify that particular lineage with the 'main line' of evolution or even with evolution itself.

Bonner is not one of those biologists. He is quite happy to talk about the evolutionary 'progression', of 'evolution from small to large' and 'evolution from simple to complex'. He is not interested in all the lineages in which evolution has gone from simple to simple, small to small (for the bacteria are still with us), or even from complex to simple, or large to small. All patterns can be found among the $10^{\circ}$ lineages available. I therefore found myself repeatedly disagreeing with Bonner. The disagreement, fortunately, is mainly about words. Neither his argument, nor his evidence, concern 'evolution' as a whole; and if every time he says 'evolution' we substitute 'evolution down the one lineage in $10^{4}$ that happens to run from the origin of life to humans beings' it usually makes equally good grammatical, and better biological, sense.

Bonner's first subject is size. From the origin of life onwards, the size of the largest kind of animal or plant present at any one time has increased. There were only unicellular organisms $3 \times 10^{\prime \prime}$ years ago: now there are blue whales, and there were dinosaurs not solong ago. Bonner explains the trend by what he calls ecological 'pioneering'. If a niche in nature is unexploited, a pioneer ecological species will soon invade it. Likewise, over evolutionary time, species will tend to evolve into places where there is reduced competition. The niches for small organisms have been filled ever since the origin of life, and progressively larger forms have been able to pioneer the niches for larger and larger types. The process, as Bonner discusses, would have been speeded up when sexual reproduction evolved - which explains my titular quotation from Arthur Guiterman. The argument is a form of Darwin's 'principle of divergence', though Bonner does not mention it.

He then shows, in what is the main original result in the book, that the histological differentiation of living things is proportional to their body size. Bonner has compiled estimates of the number of cell types in various kinds of organism. Small, unicellular organisms have one cell type, mushrooms have about seven. squids and Diptera about 55, and vertebrates more than 120 . Actually, there is no increase in the average body size between the forms with seven cell types and those with more than 120 ; but the trend is clear between the end points.

The number of cell types is Bonner's It, like size, will tend to evolve higher main criterion of organismic complexity. extreme forms by the principle of divergence, and Bonner argues that there are advantages in the division of labour too.

The book is not only about why more complex, and larger, forms have arisen later in evolution. Bonner discusses complexity in four areas of biology: genetics, embryology, ecology and animal behaviour. Behaviour is included as the pinnacle of complexity. Bonner likes analogies between principles in different fields, and he is interested, for example, in the abstract similarities between the development of behaviour and morphology. $\mathrm{He}$ does not, however, appear to have read J.W.S. Pringle's classic paper of almost 40 years ago (Behaviour 3, 90-110; 1951). Pringle discussed the analogy between learning and evolution, both more deeply and more exactly than Bonner does. Pringle defined complexity in terms of information theory, and noticed that it is characteristic of learning to increase the complexity of an organism's behaviour patterns. Like natural selection, learning increases the frequency of otherwise improbable events and builds up biological complexity as it does so.

Bonner has aimed to write a synthetic work. He draws on a wide range of evidence from the four areas of biology, and almost any biologist will learn something new. It is hardly fair to demand that another whole subject should have been included, but palaeontology is an obvious gap. Bonner has not ignored the fossil evidence, but he has made no use of the modern palaeobiological ideas on longterm evolutionary trends. He discusses trends in size and complexity purely in terms of natural selection, but (as palaeobiologists have pointed out) trends can also arise when a character is correlated with speciation, or extinction, rates. A graph in the book suggests that more complex species have higher extinction rates, although it is difficult to be sure how much of the effect is a taxonomic artefact. If more complex forms do have higher extinction rates, the force of 'species selection' will tend to decrease the level of complexity in biological systems.

Bonner has a gentle style. The Evolution of Complexity is written for the general biological reader and each concept, such as speciation, is explained in elementary terms when it first appears. He does not go in for any cheap showing off: he only discusses things he is prepared to take seriously, and does not caricature his opponents, or make spurious claims to originality. I doubt whether the book contains any important new insights. but it makes pleasant reading and may direct somebody to a new line of thought on this apparently timeless problem of evolution.

Mark Ridley is in the Department of Zoology, University of Cambridge, Downing Street, Cambridge CB2 3EJ, UK. 